\title{
Editorial \#33
}

\section{Prácticas y saberes sobre cuerpos y sexualidades}

\author{
Paula Mendes Lacerda' \\ $>$ lacerdapaula@gmail.com \\ ORCID 0000-0003-2938-8136 \\ ${ }^{1}$ Departamento de Antropología \\ Programa de Posgrado en Ciencias Sociales \\ Universidad del Estado de Río de Janeiro (UERJ)
}

Copyright ( 2019 Sexualidad, Salud y Sociedad - Revista Latinoamericana. This is an Open Access article distributed under the terms of the Creative Commons Attribution License (http creativecommons.org/licenses/by/4.0/), which permits unrestricted use, distribution, and reproduction in any medium, provided the original work is properly cited. 


\section{Prácticas y saberes sobre cuerpos y sexualidades}

A lo largo de sus 10 años de existencia, Sexualidad, Salud y Sociedad - Revista Latinoamericana ha contribuido a difundir los resultados de investigaciones procedentes de diversos países, con el foco de observación y reflexión puesto en los contextos latinoamericanos. Este número de la Revista -el 33-publica 9 artículos y una reseña, además del dossier temático titulado "Parentesco, Familia y Diversidad: controversias públicas y perspectivas etnográficas”, organizado por Naara Luna y Leandro Oliveira.

Los artículos que, aparte del dossier, componen esta edición, ponen en perspectiva saberes -y sus efectos- sobre concepciones y prácticas respecto de la sexualidad, tales como la medicina/ginecología, la pedagogía, el psicoanálisis, el derecho y la comunicación. Se trata, como podrá apreciarse, de un conjunto de artículos que, más allá de presentar reflexiones y análisis teóricos, tienen en común una crítica constructiva a aquellos saberes, en busca de una sociedad más justa, menos violenta y comprometida con la diversidad sexual y de género.

El primer artículo de este número, de Heloisa Buarque de Almeida, analiza los efectos de las campañas brasileñas contra el acoso sexual, inicialmente difundidas a través de medios alternativos. Con una perspectiva etnográfica e inspirada en Honneth (2003) y Fraser (1996), la autora describe procesos de demanda de reconocimiento social. Argumenta que, como un efecto no planificado, los cambios culturales en la percepción del acoso sexual y de otras formas de violencia contra las mujeres generaron la aparición de una nueva categoría penal, “impertinencia sexual”.

Los siguientes dos artículos, de Virginia Cano y de Núria Calafell Sala, tratan de la ginecología como campo de saber-poder disciplinador, medicalizante y patologizante, con especial incidencia sobre los cuerpos de las mujeres. El trabajo de Cano, basado en la obra de Foucault, presenta a la ginecología como un campo médico formado por un conjunto de saberes que ejercen violencia de tipo normativo y posibilitan prácticas excluyentes, a través de la transformación de la diversidad de cuerpos y de experiencias, en cuerpos cisgénero y heterosexuales. El efecto, argumenta la autora, es la producción de des/atención y de precarización de corporalidades y modos de vida lésbicos, trans, bi y pansexuales, entre otros. En contrapunto con una ciencia que excluye e invisibiliza, Calafell Sala nos muestra experiencias editoriales que buscan difundir prácticas y principios de la "ginecología natural". Para la autora, comprender y visibilizar este movimiento es efectuar una apuesta en una perspectiva descolonizante, de cuerpos y experiencias, que pueda producir efectos de descentramiento del saber médico y de su autoridad sobre las mujeres. 
El tema de la ginecología continúa en el artículo siguiente, de Oliveira, Peralta y Souza, referido a las parteras tradiciones en la región rural del Estado de Amazonas, en Brasil. A través de entrevistas, los autores analizan el trabajo de parteras que actúan en más de diez comunidades rurales, ofreciendo asistencia a parturientas y sus familias, recuperando las perspectivas de Tornquist (2005) sobre el lugar de las parteras en contextos rurales, ribereños, nativos y periféricos urbanos. En muchos casos, la asistencia de las parteras se combina con la atención medicalizada, lo que los autores analizan en términos de "encuentros y desencuentros" entre saberes. El artículo finaliza señalando la importancia de las parteras en la salud reproductiva de las mujeres de comunidades rurales, remarcando la necesidad de que esa realidad sea conocida e incorporada en la formulación de políticas públicas para las poblaciones de la Amazonia.

En "Limitaciones sociales de derechos a la sexualidad de las personas con Síndrome de Down” Luna Zaenz y Jácome Mora se ubican en el centro del análisis de normas y saberes especializados - pero también de miedos y prejuicios- como elementos que impactan el ejercicio de la sexualidad y de la construcción de subjetividad de personas con Síndrome de Down (SD). A partir del análisis de obras científicas publicadas en España, Argentina y Colombia, las autoras destacan los principales condicionantes y limitantes de la satisfacción de las necesidades afectivas y sexuales de las personas con SD. Y señalan a la familia y a la sociedad como fuentes de obstáculos, producidos en función del miedo, del estigma y de mitos sobre la sexualidad de estas personas.

El tema de las emociones y percepciones subjetivas reaparece en el texto siguiente, de Serna Botero, Cárdenas y Zamberlin. En el abordaje del "fenómeno de la objeción de conciencia" -argumento accionado por profesionales de la salud que se niegan a realizar procedimientos relacionados con la salud sexual y reproductiva- las autoras ponen en evidencia los altos costos que inciden en la vida de las mujeres ante la negativa de los profesionales involucrados. De acuerdo a las conclusiones de la investigación, en los tres países donde fue realizada (Argentina, Uruguay y Colombia) los profesionales de la salud entrevistados reproducen representaciones sobre las mujeres y sus cuerpos, como si se tratara de máquinas reproductivas.

El artículo de Ávila de Garay presenta críticas y realiza interesantes sugerencias respecto a la centralidad del género en el proceso psicoanalítico. En base a su propia experiencia clínica como psicoanalista en México, la autora propone que el género es constitutivo del proceso mismo de formación del sujeto, no sólo de aquellos que manifiestan, por caso, algún conflicto en relación a su expresión de género, o a su orientación sexual. Más allá de sus contribuciones teóricas, este artículo se propone hacer un aporte a la clínica psicoanalítica.

Las diferencias entre países con una herencia colonial, como los latinoameri- 
canos, y aquellos que no comparten tal herencia, como los países nórdicos, han sido exploradas en el trabajo de Motta y Campos sobre las políticas de bienestar social y sus efectos sobre el género. Los autores demuestran que, a pesar del fortalecimiento en las últimas décadas de políticas públicas en países latinoamericanos -que llaman la "ola rosa"- se verifica el fortalecimiento de políticas familiaristas, es decir, que interpretan el cuidado de niños y ancianos como un tema "de familia”, promoviendo así licencias de maternidad y/o paternidad. El contrapunto de ese modelo es el representado por la experiencia de los países nórdicos, en los que la tradición socialdemócrata ha significado una oferta de servicios y estructuras, públicas y colectivas, como guarderías, espacios para el cuidado de ancianos, y demás políticas que estimulan la salida de las mujeres al mercado del trabajo.

El escenario colonial y la expectativa de cambio social reaparecen en el último artículo de este número, de Enrique Bautista Rojas, que trata sobre experiencias de violencia relacionadas a la heteronormatividad en escuelas de México. Este texto puede ser entendido como una invitación a la reflexión y transformación pedagógica, tarea no sólo de la comunidad escolar, sino de toda la población.

\section{Referencias Bibliográficas}

FRASER, Nancy. 1996. "From distribution to recognition - Dilemmas of justice in a 'post-socialist' age” New Left Review, 212, July/August 1996, pp.68-93.

HONNETH, Axel. 2003. Luta por reconhecimento: A gramática moral dos conflitos sociais. São Paulo: Ed. 34.

TORNQUIST, Carmen Susan. 2005. "Parteiras populares: entre o folclore e a escuta". Gênero. $1^{\circ}$ sem. 2005. Vol. 6, n. 1, p. 61-80. 